\title{
Effects of incorporation of additives in the mechanical properties of films of linear low-density polyethylene
}

\author{
Influencia de la incorporación de aditivos en las propiedades mecánicas de películas de \\ polietileno lineal de baja densidad
}

\author{
Emilo Delgado ${ }^{1}$, William Aperador Chaparro. ${ }^{1 *}$, Juan Carrillo Leon $^{1}$ \\ ${ }^{I}$ Universidad Militar Nueva Granada, Bogotá, Colombia.
}

\begin{abstract}
In this investigation the effect of the incorporation of additives in the mechanical properties of LLDPE films, made to be used as greenhouse covers, was analyzed. All films were fabricated by the method of extrusion blow. Two types of formulations are raised in order to determine the influence of the concentration of one additive and identify the existence of some synergy by combining active ingredients in the formulations. Modulus of elasticity, yield stress and tear resistance of the films were evaluated. The results indicate that variation in the concentration of an additive in the mixture does not generate significant changes in the physical-mechanical properties of the films. However, the incorporation of the UV light absorber and Smartlight fotoselector in formulations favors their mechanical properties. Compared with the reference film, an increase higher than $200 \%$ in modulus of elasticity and yield stress of the films was determined.
\end{abstract}

Keywords: Additives, Plasticulture, LLDPE, Mechanical Properties.

\section{Resumen}

En esta investigación, se analizó el efecto de la incorporación de aditivos en las propiedades mecánicas de películas de LLDPE formuladas para su uso como cubiertas de invernadero. Todas las películas fueron fabricadas por el método de extrusiónsoplado. Se plantearon dos tipos de formulaciones con el fin de determinar la influencia de la concentración de un mismo aditivo e identificar la existencia de alguna sinergia al combinar ingredientes activos en las formulaciones. Se evaluaron el módulo de elasticidad, esfuerzo de fluencia y resistencia al rasgado de las películas. Los resultados indican que la variación en la concentración de un aditivo en la mezcla, no genera cambios significativos en las propiedades físicomecánicas de las películas. Sin embargo, la incorporación del absorbedor de luz UV y el fotoselector Smartlight en las formulaciones, favorece sus propiedades mecánicas. Se determinó un incremento superior al 200\% en el módulo de elasticidad y esfuerzo de fluencia de las películas en comparación con la película de referencia.

Palabras clave: Aditivos, Plasticultura, Polietileno Lineal de Baja densidad, Propiedades Mecánicas

\section{Introduction}

The possibility of converting absolutely unproductive desert areas on land suitable for cultivation as well as the option of its deployment in areas with limited cultivation land are some of the great advantages of the usage of growing

*Corresponding Author.

E-mail: Arnoldo.delgado@unimilitar.edu.co houses, commonly known as greenhouses [1]. Made mostly of plastic materials, which can be processed by extrusion blown into films of considerable sizes and thicknesses, with relatively good optical and mechanical properties, plus a competitive price in the market, they allow the creation of a favorable environment for the agriculture, regardless of the

How to cite: Delgado, E.., Chaparro, A.., Carrillo, J., Effects of incorporation of additives in the mechanical properties of films of linear low-density polyethylene, TECCIENCIA, Vol. 12 No. 23, 6172, 2017

DOI: http://dx.doi.org/10.18180/tecciencia.2017.23.7 


\section{TECCIENCIA}

external environment, increasing productivity and reducing dependence on climatic conditions [2].

Their usage opens the possibility of exercising control over the environment generated inside, so that you can achieve a reduction in water consumption, increase quality and crop yields and exercise greater control over the spread of pests that may affect plant development [3]-[5].

This type of cover must meet certain technical specifications for optical and thermal properties (transmission of visible and diffused light, thermicity), mechanical properties (elasticity, yield stress and tear resistance) and physical properties (thickness, length, width, weight $/ \mathrm{m} 2$ etc.) that enable them to withstand the environmental conditions to which they are exposed, ensuring the fulfillment of the task for which they have been designed, regardless of geo climatic conditions of the area. However, due to the exposure to various environmental conditions, factors such as wind, rain, cyclic changes of temperature, internal greenhouse conditions (humidity, biological activity and pesticides) [2], [6], [7], as well as fluctuations in the manufacturing process of the film, it is inevitable that the polymer undergoes a deterioration in its structure affecting physicochemical and mechanical properties of the cover [8], [9] [10]. Therefore, the evaluation of these properties is essential in determining the quality and the requirements inherent in the design and construction of greenhouses covers.

Although good results have been reported on the use of greenhouses for growing vegetables in almost desert areas or areas with extreme weather conditions [11]-[13], constant research is needed regarding the incorporation of attachments that can change the properties of these covers, so that they can meet the requirements of light, temperature and humidity of the crop, even if weather conditions are adverse, and in turn extend the life of the material. Usually, research in this field is directed towards the development and implementation of additives for absorption and stabilization of UV light and temperature control inside the greenhouse, which are specifically applied depending on crop and weather conditions the geographical area [14]. However, there is no report on how these additions can affect the mechanical properties of the films. While the main objective in design is to counteract the effects of radiation and ultraviolet [15], [16], one can not overlook that such structures must support a lot during installation and be prepared for the onslaught by external agents (wind, rain, hail etc.) during the time of service.

The purpose of this paper is to evaluate the effect of the incorporation of additives on the mechanical properties of LLDPE films manufactured by extrusion blow formulated for use as covers in growing houses, through the evaluation of tensile properties (modulus of elasticity, yield stress) and tear resistance of the films. The selection of additives was oriented towards the critical properties for the application (use in greenhouses): absorption and stabilization of UV light, thermicity and Photoselection.

\section{Materials and Methods.}

\subsection{Materials.}

The films were made from linear low density polyethylene, polymer suitable for extrusion blow molding process (Hanwha-LLDPE 3304® MI: 1,1 g/10 minute, $\square$ : 0,923 $\mathrm{g} / \mathrm{cm} 3)$. The trade name and the specific role of the additives used in the formulations are shown in Table 1.

The selection of additive concentrations is performed according to the literature and technical criteria suggested by the manufacturers [17]. It is noteworthy that UV stabilizers and absorbers migrate to the surface, therefore very thin films, for example of 40 microns, require concentrations near 1,0 part per hundred rubber (phr) unlike films with thickness of 200 microns, which may be dosed with 0,4 phr. The thermal-type additives are inorganic fillers, which do not migrate, so they can be formulated with concentrations ranging from $0,5-15 \%$ depending on crop requirements and climatic conditions of the area [18], [19]..

Table 1 Description of additives.

\begin{tabular}{|c|c|c|}
\hline $\begin{array}{l}\text { Name of } \\
\text { additive }\end{array}$ & Convention & $\begin{array}{c}\text { Description and } \\
\text { Effect of the } \\
\text { additive }\end{array}$ \\
\hline $\begin{array}{l}\text { UV } \\
\text { Stabilizer }\end{array}$ & $\mathrm{E}$ & $\begin{array}{l}\text { HALS type protects } \\
\text { from ultraviolet } \\
\text { light. }\end{array}$ \\
\hline $\begin{array}{l}\text { IR Kaolin } \\
\text { Blocker }\end{array}$ & IR & $\begin{array}{l}\text { Block the flow of } \\
\text { medium infrared } \\
\text { radiation (MIR } \\
1400-3000 \mathrm{~nm}), \\
\text { avoids heat } \\
\text { dissipation. }\end{array}$ \\
\hline UV Absorber & A & $\begin{array}{l}\text { Benzotriazole type, } \\
\text { blocks UV } \\
\text { radiation, avoids } \\
\text { deterioration in } \\
\text { plants and decreases } \\
\text { the activity of } \\
\text { insects. }\end{array}$ \\
\hline $\begin{array}{l}\text { Smartlight } \\
\text { Photoselector } \\
\text { RL } 1000\end{array}$ & $\mathrm{~S}$ & $\begin{array}{l}\text { Increases } \\
\text { productivity in } \\
\text { crops, filters UV } \\
\text { radiation and emits } \\
\text { red light. }\end{array}$ \\
\hline
\end{tabular}




\section{TECCIENCLA}

\begin{tabular}{lll}
\hline $\begin{array}{l}\text { Iriodin } \\
\text { Photoselector } \\
215\end{array}$ & 215 & $\begin{array}{l}\text { Blocks NIR* and } \\
\text { reduces overheating } \\
\text { without blocking } \\
\text { PAR** }\end{array}$ \\
\hline Red pigment & PR & $\begin{array}{l}\text { It is photoselective, } \\
\text { emits } 0.65 \text { microns } \\
\text { in the red, which is } \\
\text { maximum in } \\
\text { photosynthesis. }\end{array}$ \\
& & $\begin{array}{l}\text { It is photoselective, } \\
\text { emits } 0.45 \text { microns } \\
\text { in the blue. }\end{array}$ \\
\hline Blue pigment & PA & \\
& &
\end{tabular}

* NIR: Near Infrared

** PAR: Photosynthetically Active Radiation

In this research, the effect of addition of these additives into formulations on physical-mechanical properties of the polymer matrix is analyzed. The role of each additive in the formulation is not given in detail

\subsection{Experimental design.}

A design of a single factor experiments (each mechanical property) with several levels (number of formulations) was proposed. The variable response corresponds to the physical-mechanical property in the study: yield stress (maximum stress that can be caused the material with no deformation), elastic modulus (measure of the resistance to elastic deformation), thickness and tear resistance.

\subsection{Films formulations.}

Films with two types of formulations were prepared: a) formulations with different percentages of one additive, in which the influence of the concentration for the same active ingredient is evaluated and b) formulations with multiple additives that allow us to identify if there is any synergy when combining active ingredients.

\subsubsection{Formulations with a single additive.}

Five kinds of additives of three different concentrations were used, thereby obtaining 15 formulations as shown in Table 2 . The results obtained will be compared with the properties of LLDPE 3304 film without additives.

\subsubsection{Formulations with multiple additives.}

Using the additives mentioned in Table 1, six different formulations were prepared, as can be seen in Table 3 .

\subsection{Preparation of films}

The film manufacturing process consists of the following stages: mixing, grinding, pelletizing and blowing, as described below:

\subsubsection{Mixing and grinding.}

This stage was done in a Brabender plastic-corder PLE331 internal mixer of tangential rotors. To reduce the size of the mixture a laboratory blade mill was used.

2.4.2 Pelletizing. It was performed in the Brabender module consisting of an extrusion system, a die with double rheological cylindrical channel for extruding the mixed material cords, a tank for cooling and solidifying the material and a final granulator.

2.4.3 Blowing. A Brabender Plasticorder PLE 331 was used, with a screw 047 , one staged, compression ratio of 4 to 1 , ratio of length to diameter (L / D) $25: 1,3 / 4$ inch diameter, 25 threads. Operating variables are presented in Table 4.

\subsection{Preparation of films}

The film manufacturing process consists of the following stages: mixing, grinding, pelletizing and blowing, as described below:

\subsubsection{Mixing and grinding.}

This stage was done in a Brabender plastic-corder PLE331 internal mixer of tangential rotors. To reduce the size of the mixture a laboratory blade mill was used.

\subsubsection{Pelletizing.}

It was performed in the Brabender module consisting of an extrusion system, a die with double rheological cylindrical channel for extruding the mixed material cords, a tank for cooling and solidifying the material and a final granulator.

\subsubsection{Blowing.}

A Brabender Plasticorder PLE 331 was used, with a screw 047, one staged, compression ratio of 4 to 1 , ratio of length to diameter (L / D) 25: 1, 3/4 inch diameter, 25 threads. Operating variables are presented in Table 4.

\subsection{Determining the physical mechanical properties}

\subsubsection{Thickness measurement.}

The thickness measurement was performed using a model $549 \mathrm{MM}$ micrometer by Testing Machine Inc. In all tests the specimen thickness was measured prior to testing. All tests were performed under controlled conditions of relative humidity of $50 \%$ and temperature of $22{ }^{\circ} \mathrm{C}$. 


\section{TECCIENCLA}

\subsubsection{Tear resistance.}

Computer. For each formulation 10 specimens were used and the force required for the propagation of a crack was measured.

\subsubsection{Yield stress and modulus of elasticity.}

Stress tests were performed on a universal testing machine Sintech $200 / 2 \mathrm{~W}$ with optical precision encoder to measure
Tear resistance tests were performed according to ASTM D1922 standard, on a Lorentzen Wettre Elmendorf LWAB the position, $50 \mathrm{~N}$ load cell, pneumatic vice, speed of 500 $\mathrm{mm} / \mathrm{min}$, load limit of $45 \mathrm{lb}-\mathrm{f}$ and a sensitivity of $99 \%$, according to ASTM D 882 standard. In each test 10 rectangular specimens of $1 \times 4$ In were used for each type of film.

Table 2 Formulations

of LLDPE with a single additive

\begin{tabular}{|c|c|c|}
\hline Formula Description & Formula Title & $\begin{array}{c}\text { Additive } \\
\text { Concentration } \\
(\% w)\end{array}$ \\
\hline \multirow{3}{*}{ LLDPE + UV Stabilizer } & 1 & 0,70 \\
\hline & 2 & 1,25 \\
\hline & 3 & 1,50 \\
\hline \multirow{3}{*}{ LLDPE + IR Kaolin Blocker } & 4 & 0,60 \\
\hline & 5 & 0,80 \\
\hline & 6 & 1,00 \\
\hline \multirow{3}{*}{ LLDPE + UV Absorber } & 7 & 0,20 \\
\hline & 8 & 0,40 \\
\hline & 9 & 0,60 \\
\hline \multirow{3}{*}{ LLDPE + Smartlight Photoselector RL 1000} & 10 & 0,60 \\
\hline & 11 & 0,80 \\
\hline & 12 & 1,00 \\
\hline \multirow{3}{*}{ LLDPE + Iriodin Photoselector 215} & 13 & 0,60 \\
\hline & 14 & 0,80 \\
\hline & 15 & 1,00 \\
\hline
\end{tabular}

Table 3 Formulations of LLDPE with multiple additives

\begin{tabular}{llllllll}
\hline \multirow{2}{*}{ Formula Title } & \multicolumn{7}{c}{ Additives Concentration (\%w) } \\
\cline { 2 - 7 } & E & IR & A & S & 215 & PR & PA \\
\hline 16 & 1,25 & 8,00 & & & & & \\
17 & 1,25 & 8,00 & 0,40 & & & & \\
18 & 1,25 & 8,00 & & 1,00 & & & \\
19 & 1,25 & 5,00 & & & 1,00 & & \\
20 & 1,25 & 8,00 & & & 1,00 & \\
21 & 1,25 & 8,00 & & & & & 1,00 \\
\hline
\end{tabular}




\section{TECCIENCLA}

Table 4 Conditions of Plasticorder Brabender PLE 331 stabilization

\section{Results}

\begin{tabular}{lc}
\hline Variable & Set Value \\
\hline Temperature in the feeding zone $\left({ }^{\circ} \mathrm{C}\right)$ & 160 \\
Temperature in the transition zone $\left({ }^{\circ} \mathrm{C}\right)$ & 220 \\
Temperature in the metering zone $\left({ }^{\circ} \mathrm{C}\right)$ & 220 \\
Temperature on the die $\left({ }^{\circ} \mathrm{C}\right)$ & 220 \\
Pump zone pressure of $7500 \mathrm{psi}(\%)$ & 39,90 \\
Maximum supported torque $(\%)$ & 31 \\
Screw speed (rpm) & 60 \\
Calender speed (rpm) & 20 \\
Residence of the material in the screw (min) & 2 \\
\hline
\end{tabular}

An analysis of variance with $95 \%$ confidence was performed using the STATGRAPHICS ${ }^{\circledR}$ PLUS 5.0 software to compare the effect of each of the formulations on the mechanical properties of the films.

\subsection{Films with a single additive}

3.1.1 Thickness:
Ten (10) thickness measurements were made for each of the fifteen formulations (high, medium and low concentrations for each additive); the average size of the film was 191,10 $\square \mathrm{m}$. From the analysis of variance, it was determined that statistically there is a significant difference in the average thickness in formulations 2, 4, 5, 6, 7, 8 and 13 (See Table 5 and Figure 1).

Table 5 Analysis of variance for Thickness - Films with a single additive

\begin{tabular}{lccccc}
\hline \multicolumn{7}{c}{ Analysis of Variance } \\
\hline \multicolumn{1}{c}{ Source } & Sum of Squares & Degree free & Mean Square & F-Ratio & P-Value \\
\hline Between groups & 50950,70 & 14 & 3639,33 & 22,39 & 0,0000 \\
Within groups & 21945,90 & 135 & 162,56 & & \\
Total (Corr.) & 72896,6 & 146 & & & \\
\hline
\end{tabular}

As can be seen in Figure 1, in making the means comparison analysis, it was found that formulations with IR Kaolin Blocker (4, 5 and 6) are the ones that present the most variation in size in each of their concentrations. It is assumed that the size differences outside the means may be related to fluctuations during the manufacturing process of the films.

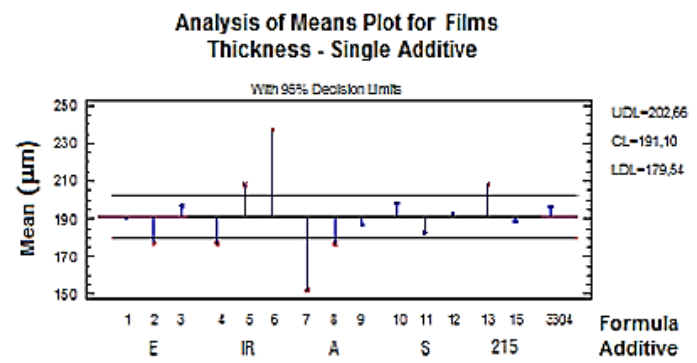

Figure 1 Analysis - of thickness Films with a single additive

\subsubsection{Tear resistance.}

Fifteen formulations (high, medium and low concentrations for each additive) were analyzed. For each formulation, ten (10) measurements were performed. The probability calculated by the ANOVA was less than 0,05 , indicating that there is a significant difference of average tear resistance in films 3, 4, 5, 6, 12 and 15 (see Table 6, Figure 2).

The value of tear resistance in formulations with IR Kaolin blocker (IR) (4, 5 and 6) are outside the average $(410,67 \mathrm{gf})$ and are related with size data, as the smallest tear value (formula 4) is the film with reduced thickness (formula 4, Figure 1). However, the ASTM D1922 standard clarifies that there is no direct relationship between this property and the caliber of the film. On comparing the tear resistance of the films with additives and LLDPE reference film it is evident in most of the cases that the incorporation of these substances into the polymer matrix decreases the value of this property in films. Furthermore, it was observed that in 


\section{TECCIENCLA}

none of the formulations there is a direct relationship between the value of the tear resistance of the film and additive concentration.

Table 6. Analysis of variance for Tear resistance - Films with a single additive

\begin{tabular}{lccccc}
\hline \multicolumn{7}{c}{ Analysis of Variance } & & \\
\hline \multicolumn{1}{c}{ Source } & Sum of Squares & Degree free & Mean Square & F-Ratio & P-Value \\
\hline Between groups & 154351,0 & 14 & 11025,1 & 8,05 & 0,0000 \\
Within groups & 184934,0 & 135 & 1369,88 & & \\
Total (Corr.) & 339285,0 & 149 & & & \\
\hline
\end{tabular}

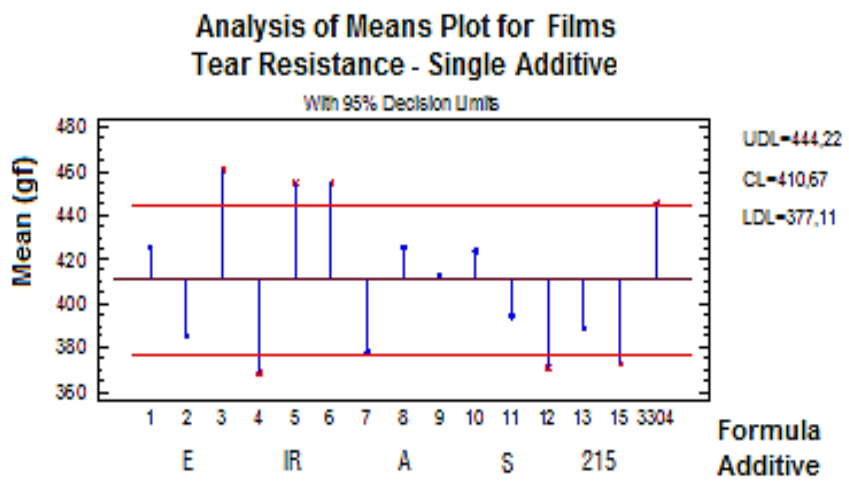

Figure 2. Analysis of tear resistance - Films with a single additive

3.1.3 Yield stress. Forty (40) trials in total for eleven formulations (additive concentration, high and low) were performed. It was found that the average yield stress of the films was 10,97 MPa, as shown in Figure 3. Based on the information obtained from the analysis of variance it was determined that there is a statistically significant change (probability calculated less than 0,05 ) in the average yield stress in film 12 (LLDPE + Smartlight photoselector (S) $1,00 \% \mathrm{w}$ ) which is found well below the average.

Table 7. Analysis of variance for Yield Stress- Films with a single additive

\begin{tabular}{lccccc}
\hline \multicolumn{1}{c}{ Source } & Sum of Squares & Degree free & Mean Square & F-Ratio & P-Value \\
\hline Between groups & 38,1117 & 10 & 3,81117 & 7,46 & 0,0000 \\
Within groups & 14,8144 & 29 & 0,510842 & & \\
Total (Corr.) & 52,9261 & 39 & & & \\
\hline
\end{tabular}

On comparing the yield stress of the different formulations with LLDPE reference film, it was clearly seen that the incorporation of Smartlight photoselectors RL 1000 and Iriodin 215 decrease the strain that the films can withstand without any deformation. In the rest of the formulas, this property does not show statistically significant change with variation in the concentration of the additive (see Table 7 , Figure 3). 


\section{TECCIENCIA}

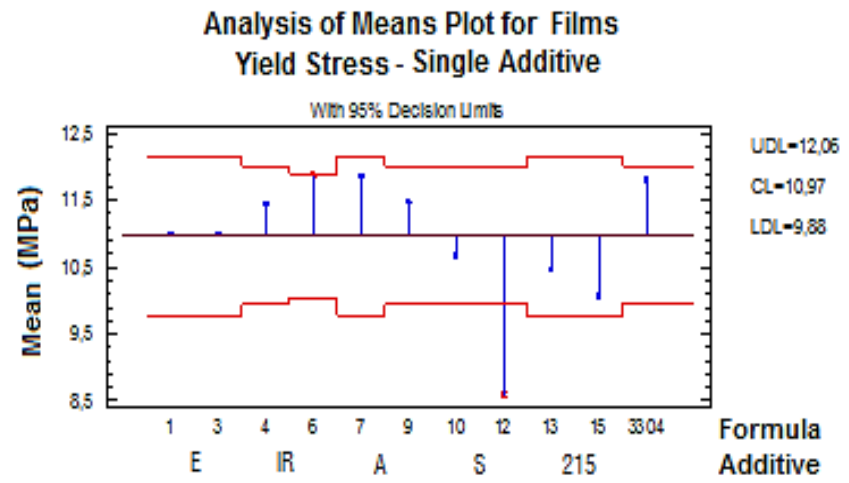

Figure 3 Analysis of yield stress - Films with a single additive

3.1.4 Modulus of elasticity. Forty (40) trials in total for eleven formulations (additive concentration, high and low) were performed. The average modulus of elasticity of the films was $105,88 \mathrm{MPa}$, as shown in Figure 4. From the analysis of variance, it was determined that there is a significant difference in the average modulus of elasticity in film 9 (LLDPE + UV absorber 0,60\% w).

Table 8. Analysis of variance for Modulus of elasticity- Films with a single additive

\begin{tabular}{lccccc}
\hline \multicolumn{1}{c}{ Analysis of Variance } \\
\hline \multicolumn{1}{c}{ Source } & Sum of Squares & Degree free & Mean Square & F-Ratio & P-Value \\
\hline Between groups & 9551,68 & 10 & 955,168 & 3,73 & 0,0026 \\
Within groups & 7424,63 & 29 & 256,022 & & \\
Total (Corr.) & 16976,3 & 39 & & & \\
\hline
\end{tabular}

As in the yield stress, the incorporation of photoselector additives in the formulations decreased the modulus of elasticity of the films compared to the 3304 LLDPE reference film. In the rest of the formulas, this property does not present a significant change with variation in the concentration of the additive (see Table 8, Figure 4).

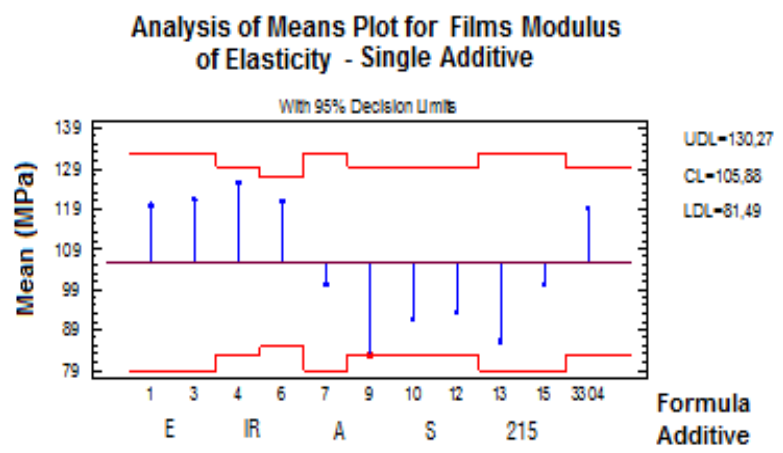

Figure 4. Analysis of the modulus of elasticity - Films with a single additive

\subsection{Films with multiple additives}

\subsubsection{Thickness.}

Seven formulations were tested and ten (10) measurements were performed by formulation. The average caliber of the film was 190,35 microns, as shown in Figure 5. From the analysis of variance, it was established that formulation 19 (LLDPE + UV stabilizer (E) + IR kaolin blocker (IR) + Iriodin 215 photoselector (215)) presented a significant difference in average thickness compared to other formulations; on comparing the results obtained with 


\section{TECCIENCIA}

thickness of LLDPE 3304 reference film, it is evident how the incorporation of these additives greatly increased the thickness of the film

Table 9. Analysis of variance for Thickness - Films with multiple additives

\begin{tabular}{lccccc}
\hline \multicolumn{5}{c}{ Analysis of Variance } \\
\hline Source & Sum of Squares & Degree free & Mean Square & F-Ratio & P-Value \\
\hline Between groups & 39944,1 & 6 & 6657,36 & 10,79 & 0,0000 \\
Within groups & 38862,8 & 63 & 616,87 & & \\
Total (Corr.) & 78806,9 & 69 & & & \\
\hline
\end{tabular}

In the rest of the formulas this property didn't present any statistically significant change with the variation of the additive, however, it is clear that in general the thickness of the films decreased with the addition of additives, except in formulation 19 (See Table 9, Figure 5).

\subsubsection{Tear resistance.}

Ten (10) measurements of the tear resistance were performed for each of the seven formulations; the average

\section{Analysis of Means Plot for Films Thickness - Multiple Additives}

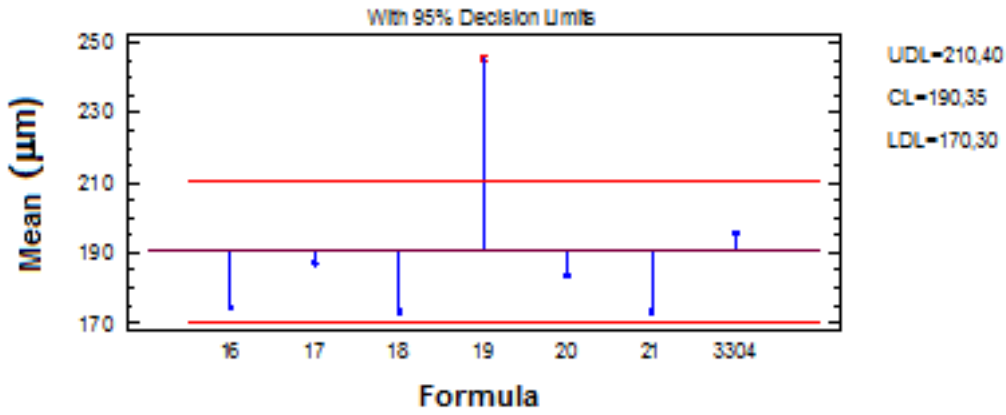

Figure 5. Analysis of thickness - Films with multiple additives

Table 10. Analysis of variance for Tear resistance - Films with multiple additives

\begin{tabular}{lccccc}
\hline \multicolumn{5}{c}{ Analysis of Variance } \\
\hline \multicolumn{1}{c}{ Source } & Sum of Squares & Degree free & Mean Square & F-Ratio & P-Value \\
\hline Between groups & 46379,9 & 6 & 7729,98 & 1,34 & 0,2548 \\
Within groups & 364595,0 & 63 & 5787,23 & & \\
Total (Corr.) & 410975,0 & 69 & & & \\
\hline
\end{tabular}

for this property was 468,11 gf, as shown in Figure 6. The formulations made with multiple additives had no gnificant difference between the average tear resistance of flims, therefore, it is understood that the mixture of additives had no effect on this property (see Table 10 and Figure 6). 


\section{TECCIENCIA}

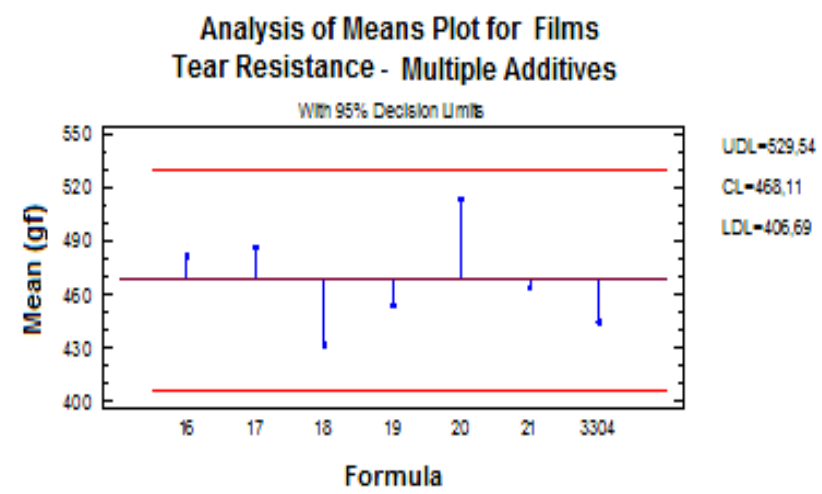

Figure 6. Analysis of tear resistance - Films with múltiples additives

Although according to ASTM D1922 standard there is no direct relationship between this property and the caliber of the film, it was expected that film 19 (LLDPE + UV stabilizer (E) + IR kaolin blocker (IR) + Iriodin photoselector 215 (215)) will present greater tear resistance compared to the others because of having the highest thickness (See formula 19, Figure 6), a situation that did not happen.

\subsubsection{Modulus of elasticity and yield stress.}

Thirty-three (33) trials in total for seven formulations were tested. The probability calculated from the analysis of variance was less than 0,05 , indicating that there is a significant difference in the average of the modulus of elasticity (see Table 11, Figure 7 (a)) and yield stress (see Table 12, Figure 8 (a)) in formulations 17 and 18.

In 7a) and 8a) Figures we see that all the films are outside of the mean $(206,78 \mathrm{MPa}$ for the modulus of elasticity and $18,45 \mathrm{MPa}$ for the yield stress), which is due to the influence of the values of formulas 17 and 18 in its calculation. Based on this, an analysis was performed excluding these formulations (see Figures 7 (b) and 8 (b)), where it was observed that the average modulus of elasticity and yield stress of the films analyzed do not present significant variation apart from formulation 19 in the yield stress.

Table 11. Analysis of variance for Modulus of Elasticity - Films with multiple additives

\begin{tabular}{lccccc}
\hline \multicolumn{5}{c}{ Analysis of Variance } \\
\hline \multicolumn{1}{c}{ Source } & Sum of Squares & Degree free & Mean Square & F-Ratio & P-Value \\
\hline Between groups & 537579,0 & 6 & 89596,4 & 41,03 & 0,0000 \\
Within groups & 56781,1 & 26 & 2183,89 & & \\
Total (Corr.) & 594360,3 & 32 & & & \\
\hline
\end{tabular}

(a)

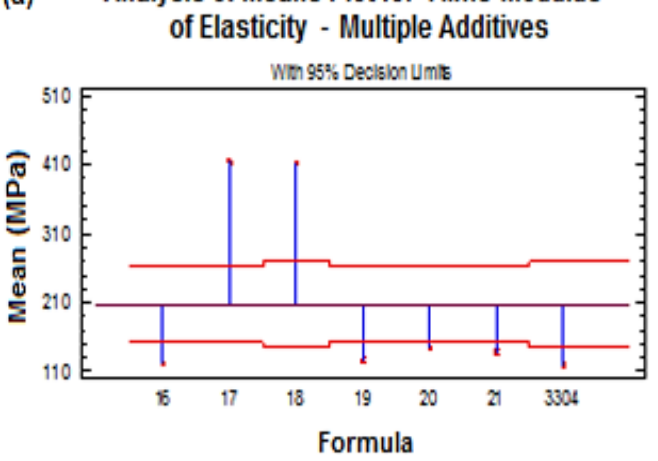

(b)

Analysis of Means Plot for Films Modulus

of Elasticity - Multiple Additives

(Without formulas 17 and 18)

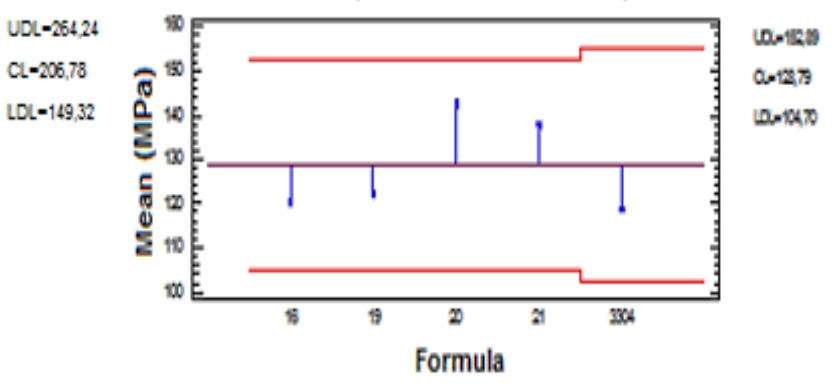

Figure 7. Modulus of elasticity - Films with multiple additives 


\section{TECCIENCLA}

Table 12. Analysis of variance for Yield stress - Films with multiple additives

\begin{tabular}{lccccc}
\hline \multicolumn{7}{c}{ Analysis of Variance } \\
\hline \multicolumn{1}{c}{ Source } & Sum of Squares & Degree free & Mean Square & F-Ratio & P-Value \\
\hline Between groups & 4956,89 & 6 & 826,148 & 567,98 & 0,0000 \\
Within groups & 37,8178 & 26 & 1,45453 & & \\
Total (Corr.) & 4994,71 & 32 & & & \\
\hline
\end{tabular}

(a)

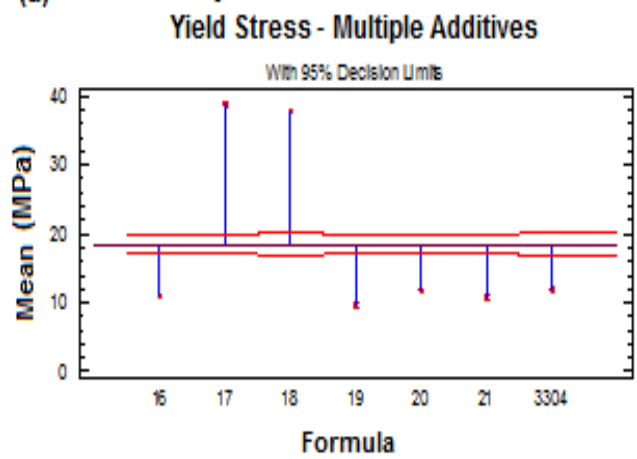

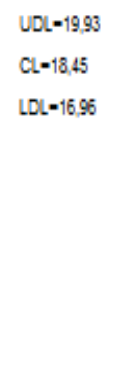

(b) Analysis of Means Plot for Films

Yield Stress - Multiple Additives

(Without formulas 17 and 18)

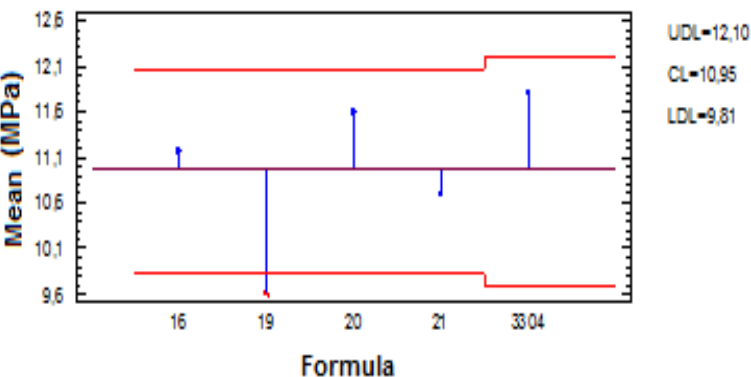

Figure 8. Yield stress - Films with multiple additives

Formulation $17(\mathrm{LDPE}+\mathrm{UV}$ stabilizer $(\mathrm{E}))+$ IR kaolin blocker (IR) + UV light absorber (A)) and 18 (LLDPE + UV stabilizer (E) + IR kaolin blocker (IR) + Smartlight photoselector (S)) presented an increase over $200 \%$ in the modulus of elasticity and the yield stress, compared to the LLDPE 3304 reference film. On analyzing the composition of these mixtures, it was found that the main difference with other formulations was the presence UV absorber (A) and Smartlight photoselector $(\mathrm{S})$. These results clearly indicate that their addition, besides fulfilling its function as modifiers of the optical and thermal properties of the films, enhance the mechanical properties of the films.

Based on this, it follows that these additives have a synergistic effect, therefore, they are responsible for the significant increase of the modulus of elasticity and yield stress of the films. However, because of the concentrations these additives were mixed in ((UV light absorber (A) $0,40 \%$ w, Smartlight photoselector (S) 1,00\%w) were low, it is necessary to conduct additional trials to confirm these results.

Furthermore, it should be noted that by the comparative analysis of the mechanical properties of the films with a single or more additives we can verify the quality of the inclusion of these substances in polymer matrix. The decrease in values compared to the standard film may indicate the existence of points of failure due to the low dispersion and homogenization of the additives in the mix.
Additionally, one should take into account that the mechanical properties of the films may have been affected by the variables of extrusion blow molding process, the melting temperature of the polymer, the die parameters, the expansion ratio, the speed conditions of spinning and cooling (Dehbi \& Mourad, 2011).

\section{Conclusions}

The influence of the incorporation of additives in the physical mechanical properties of LLDPE films made for usage as cover in growing houses was analyzed. In general, in films made with a single additive no significant changes were obtained in the physical-mechanical properties, except for some variations in thickness of the films. Incorporating an additive in the formulations in most cases led to the reduction of the tear resistance of the films with compared to 3304 reference film. No evidence of a relationship between the value of the evaluated properties and additive concentration was found.

The additive mixture has no significant influence on the tear resistance of the films. The incorporation of the UV light absorber and Smartlight photoselector in formulations strengthens the mechanical properties of the films. An increase over $200 \%$ in the modulus of elasticity and yield stress was determined compared to LLDPE pattern film. 


\section{TECCIENCLA}

Additional studies are needed to verify the existence of a synergistic effect between the UV light absorber (CGX UVA006®) and the additive photo-selector (Smartlight RL 100®) with UV stabilizer and IR blocker in LLDPE films

\section{References}

[1] A. E Kabeel y E. M. S. El-Said, «Water production for irrigation and drinking needs in remote arid communities using closed-system greenhouse: A review», Eng. Sci. Technol. Int. J., vol. 18, n.o 2, pp. 294-301, jun. 2015.

[2] S. Kumar Sen y S. Raut, «Microbial degradation of low density polyethylene (LDPE): A review», J. Environ. Chem. Eng., vol. 3, n.o 1, pp. 462-473, mar. 2015.

[3] I. M. Al-Helal y A. M. Alhamdan, «Effect of arid environment on radiative properties of greenhouse polyethylene cover», Sol. Energy, vol. 83, n.o 6, pp. 790-798, jun. 2009.

[4] J. J. Casas, S. Bonachela, F. J. Moyano, E. Fenoy, y J. Hernández, «Chapter 3 - Agricultural Practices in the Mediterranean: A Case Study in Southern Spain A2 - Preedy, Victor R.», en The Mediterranean Diet, R. R. Watson, Ed. San Diego: Academic Press, 2015, pp. 23-36.

[5] N. L. Panwar, S. C. Kaushik, y S. Kothari, «Solar greenhouse an option for renewable and sustainable farming», Renew. Sustain. Energy Rev., vol. 15, n.o 8, pp. 3934-3945, oct. 2011.

[6] F. J. Cabrera, A. Baille, J. C. López, M. M. González-Real, y J. Pérez-Parra, «Effects of cover diffusive properties on the components of greenhouse solar radiation», Biosyst. Eng., vol. 103, n.o 3, pp. 344-356, jul. 2009

[7] I. Impron, S. Hemming, y G. P. A. Bot, «Effects of cover properties, ventilation rate, and crop leaf area on tropical greenhouse climate», Biosyst. Eng., vol. 99, n.o 4, pp. 553-564, abr. 2008.

[8] A. M. Alhamdan y I. M. Al-Helal, «Mechanical deterioration of polyethylene greenhouses covering under arid conditions», J. Mater. Process. Technol., vol. 209, n.o 1, pp. 63-69, ene. 2009.

[9] D. Briassoulis, «The effects of tensile stress and the agrochemical Vapam on the ageing of low density polyethylene (LDPE) agricultural films. Part I. Mechanical behaviour», Polym. Degrad. Stab., vol. 88, n.o 3, pp. 489-503, jun. 2005.
[10] F. D. B. Castillo, G. R. Rodríguez, C. F. C. Cabrera, N. S. Melo y W. A. A. Chaparro, «Détermination of the probability and rate of corrosion on reinforced concrete specimens through a remote corrosion monitoring system,» Tecciencia, pp. 27-32, 2015.

[11] N. Banaeian, M. Omid, y H. Ahmadi, «Energy and economic analysis of greenhouse strawberry production in Tehran province of Iran», Energy Convers. Manag., vol. 52, n.o 2, pp. 1020-1025, feb. 2011.

[12] B. Khoshnevisan, S. Rafiee, M. Omid, H. Mousazadeh, y S. Clark, «Environmental impact assessment of tomato and cucumber cultivation in greenhouses using life cycle assessment and adaptive neuro-fuzzy inference system», J. Clean. Prod., vol. 73, pp. 183-192, jun. 2014.

[13] Y. Rouphael y G. Colla, «Radiation and water use efficiencies of greenhouse zucchini squash in relation to different climate parameters», Eur. J. Agron., vol. 23, n.o 2, pp. 183-194, sep. 2005.

[14] E. Espí, A. Salmerón, A. Fontecha, Y. García, y A. I. Real, «PLastic Films for Agricultural Applications», J. Plast. Film Sheeting, vol. 22, n.o 2, pp. 85-102, abr. 2006.

[15] C. Lamnatou y D. Chemisana, «Solar radiation manipulations and their role in greenhouse claddings: Fresnel lenses, NIR- and UVblocking materials», Renew. Sustain. Energy Rev., vol. 18, pp. 271 287 , feb. 2013

[16] C. Stanghellini, J. Dai, y F. Kempkes, «Effect of near-infraredradiation reflective screen materials on ventilation requirement, crop transpiration and water use efficiency of a greenhouse rose crop», Biosyst. Eng., vol. 110, n.o 3, pp. 261-271, nov. 2011.

[17] A. E. Delgado, W. A. Chaparro, y J. R. S. Gonzalez, «Influencia del porcentaje de mezcla del aceite de higuerilla en la obtención de combustible alternativo para motores diesel», Revista Facultad de Ingeniería Universidad de Antioquia, vol. 58, pp. 46-52, marzo 2011.

[18] A. P. Papadopoulos y X. Hao, «Effects of greenhouse covers on seedless cucumber growth, productivity, and energy use», Sci. Hortic., vol. 68, n.o 1-4, pp. 113-123, mar. 1997.

[19] J. M. Peña, N. S. Allen, M. Edge, C. M. Liauw, y B. Valange, «Studies of synergism between carbon black and stabilisers in LDPE photodegradation», Polym. Degrad. Stab., vol. 72, n.o 2, pp. 259270 , may 2001

[20] A. Dehbi y A.-H. I. Mourad, «Durability of mono-layer versus trilayers LDPE films used as greenhouse cover: Comparative study», Arab. J. Chem., vol. 9, Supplement 1, pp. S282-S289, sep. 2016. 